\title{
ANALYSIS METHODS FOR CFRP BLAST RETROFITTED REINFORCED CONCRETE WALL SYSTEMS
}

\author{
G.L. PEZZOLA ${ }^{1}$, L.K. STEWART ${ }^{1}$, \& G. HEGEMIER ${ }^{2}$ \\ ${ }^{1}$ School of Civil and Environmental Engineering, Georgia Institute of Technology, USA. \\ ${ }^{2}$ Jacobs School of Engineering, University of California San Diego, USA.
}

\begin{abstract}
A blast retrofit technique for concrete structures using carbon fiber-reinforced polymer (CFRP) layers was investigated for use in large infrastructure systems with the overarching goal of preventing against major loss of life and considerable damage that would require extensive repair. Large-scale experiments were conducted and the retrofit behavior was investigated for application on relatively large reinforced concrete walls subjected to blast-like loadings. The experimental program utilized the University of California San Diego (UCSD) Blast Simulator. The Blast Simulator is able to induce various blast-like shock waves to the test specimen in a controlled laboratory environment. The performance of this blast retrofit was tested and then analyzed using SDOF and finite element modeling methods. A finite element model was created using LS-DYNA and utilized contact algorithms for the CFRP-concrete interface. Results and comparisons between the two analysis methods are given. Keywords: blast, CFRP, finite element, reinforced concrete, SDOF.
\end{abstract}

\section{INTRODUCTION}

Fiber-reinforced polymer (FRP) laminates have been shown in many studies to effectively retrofit and repair reinforced concrete structural elements [1-5]. The use of FRP as a retrofit is popular as it can be installed post-construction to strengthen the structure. It allows for fast installation, and has a very high stiffness and tensile strength $[6,7]$. Often times anchorage systems are used to mechanically restrain the FRP and to prevent delamination between the FRP and concrete, and in order to try and achieve the full tensile capacity of the FRP. Many tests have been conducted and the results are mixed and inconclusive [8-10].

The performance of anchorage systems in retrofits is extremely important, as failure modes of the FRP are not tensile failures, but failures due to local stress concentrations by the anchors and delamination of the FRP to the concrete [1, 11-14]. These failures are much more sudden and less ductile than a tensile strength failure of the FRP, which emphasizes the need to achieve an anchoring system that allows the FRP to achieve full tensile failure.

\section{EXPERIMENTAL PROGRAM}

\subsection{Blast simulator}

The Blast Simulator has been proven to deliver blast-like impulses without the use of explosive materials [15]. The setup of the Blast Simulator is shown in Fig. 1. Because there is no fireball, the behavior of the specimen can be easily documented. This is accomplished using 


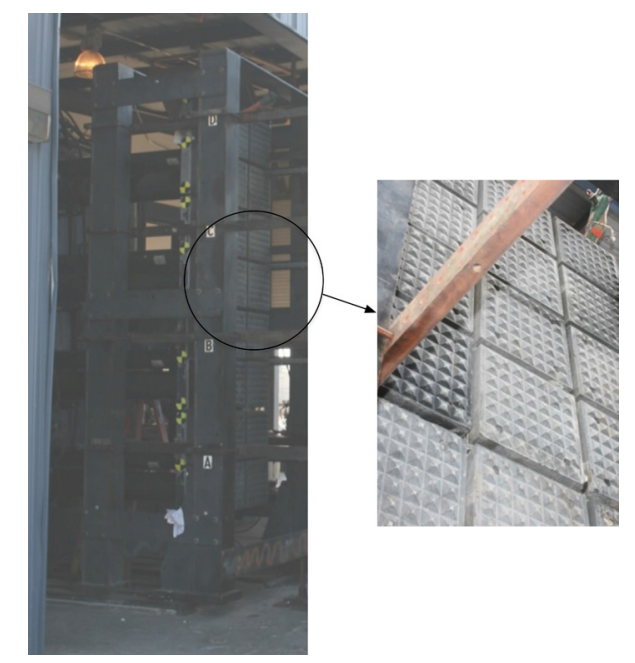

Figure 1: Blast Simulator (left) and programmers (right).

impacting masses attached to an array of high-velocity hydraulic actuators driven by a combined high-pressure nitrogen/hydraulic energy source.

To achieve the necessary pressures, nitrogen is first pumped into an accumulator where a volume of oil is compressed to high pressure (approximately $35 \mathrm{MPa}(5,000 \mathrm{psi})$ ). The oil flow into the acceleration port of the actuator is regulated through ultra high-speed servo controlled poppet valves. The poppet valves are opened and the pressurized oil drives the piston/impacting mass assembly towards the specimen. On impact, the return poppet valve opens and a deceleration chamber filled with pressurized nitrogen forces the oil out, which retracts the impacting mass. Pressure transducers and magnetostrictive position sensors give precise feedback on the accumulator pressures and impactor positions. Attached to the rod is the impacting module which consists of an aluminum mass for these tests, a thin aluminum backing plate, and a nonlinear urethane material called a programmer (Fig. 1). The programmer is used to transfer energy and momentum of the Blast Simulator to the specimen. The programmer was designed in geometry and material to deliver blast-like pulses. The pyramid-like face of the programmers helps to control the duration of the pressure to better represent blast loads.

The Blast Simulator was used in the study described in this paper to observe, analyze, and model the behavior of the system for various blast parameters. Quantitative and qualitative data were used to calibrate and validate the numerical models.

\subsection{Test specimen and setup}

Two test articles were tested and were identical in construction. The test articles consisted of a reinforced concrete specimen of dimensions $1.2 \mathrm{~m}$ (48 in) wide, $4.3 \mathrm{~m}$ (171 in) tall and $0.3 \mathrm{~m}$ (12 in) thick. The width and thickness of the specimen were near the upper range in terms of surface area of what the blast generator arrangement is capable of testing in order to apply uniform loading and have sufficient boundary conditions that best simulated the existing structure. The nominal concrete strength was $35 \mathrm{MPa}(5,000 \mathrm{psi})$. The specimen was 

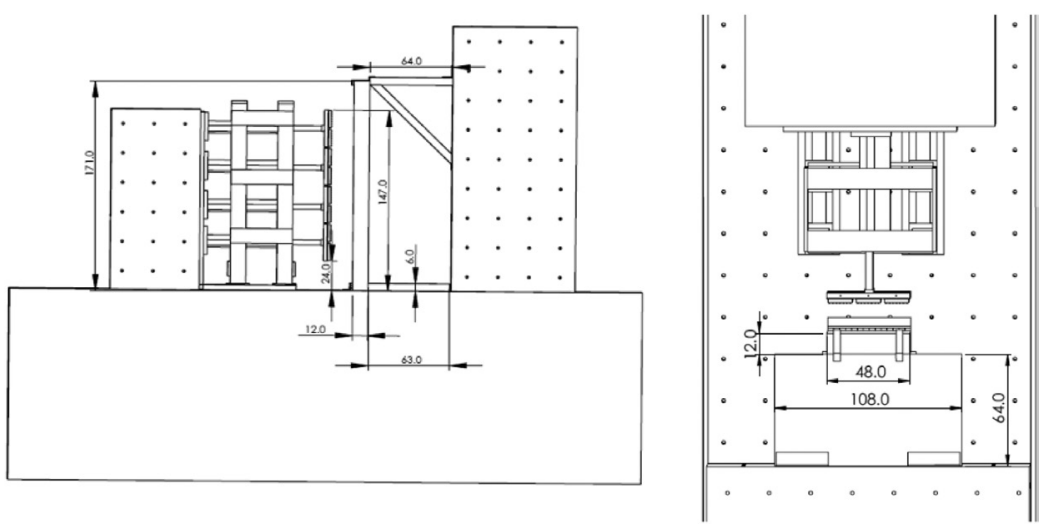

Figure 2: Schematic of test setup from side (left) and top (right). (Units are in inches).

wrapped with four layers of MBrace CF 160, two layers in the 0 degree (along the length) direction and two layers in the 90 degree (width) direction. Only the"back" side (the side that was not impacted by the blast generators) was reinforced with the CFRP. The sides remained unwrapped in order to better view the propagation of damage in the wall thickness, as well as to better emulate existing structures of interest. The rebar schedule in the test specimens was designed so that the failure modes would simulate those that would be observed in existing structures. Therefore, the test specimens were heavily reinforced in shear throughout the specimen. The CFRP was anchored at approximately 4 foot spacing.

A schematic of the test setup is shown in Fig. 2. Four blast generators (referred to as BGs, capable of delivering up to $30 \mathrm{~m} / \mathrm{s}$ impacts to the specimen) were used to deliver a uniform blast load. The impacting masses of the blast generators were the same width as the test specimen and $3.1 \mathrm{~m}$ (123 in) tall, set up to impact the specimen in a symmetric manner. Three Phantom cameras, running at 5,000 frames per second, together with TEMA tracking software, were employed to determine displacement, velocity and acceleration time histories of targets placed on the specimen. In addition, an LVDT (linear variable differential transformer) together with an array of accelerometers and strain gages were used throughout the specimen. The LVDT was located at the middle of the specimen (mid-width and mid-height). Three accelerometers were distributed on the centerline of the backside of the wall throughout the height of the specimen. Six strain gages were placed on the back of the specimen attached to the last layer of the composite for each test. The impact velocity for the first test $(22.5 \mathrm{~m} / \mathrm{s})$ was selected to create strains in the CFRP in the range of 1\%-2\% (within the range of strain failure of the CFRP, as reported in coupon test data).

\subsection{Experimental results}

Strain gage data and qualitative results were recorded and pressure and impulse time histories were calculated for the two tests. For each test, some of the strain gages failed and no real data could be obtained from them. The peak strain obtained from the strain gages in the $17 \mathrm{~m} / \mathrm{s}$ test was $0.84 \%$, and the peak strain obtained from the strain gages in the $22 \mathrm{~m} / \mathrm{s}$ test was $0.9 \%$.

The maximum displacement of the midpoint for the $17 \mathrm{~m} / \mathrm{s}$ test was approximately $10.1 \mathrm{~cm}$ (4 in), while the maximum displacement of the midpoint for the $22 \mathrm{~m} / \mathrm{s}$ test was approximately $33.0 \mathrm{~cm}$ (13 in), measured using tracking software. 
The pressure and impulse time histories were derived from the accelerometer data on the BGs and the hydraulic data from the blast simulator, as proven to be an acceptable way of calculating the pressure and impulse time histories in the research performed by Freidenberg [16]. This method calculates the pressure and impulse time histories by first calculating the force imparted to the specimen as a function of time by adding the contribution of the hydraulic force and the product of the mass and acceleration data of the impacting masses. The hydraulic force is calculated using the pressure transducer data from both the acceleration chamber (which drives the piston towards the specimen) and the deceleration chamber (which drives the piston away from the specimen) and the areas of the two chambers. Once the force imparted to the specimen is calculated, the impact area can be used to derive the pressure time histories. The pressure time histories are then numerically integrated using the trapezoidal rule to obtain the impulse time histories. It should be noted that this methodology does not always result in a zero-force before impact. This could be due to a number of factors - unphysical noise in the accelerometer data or any error in the hydraulic data. An ad hoc factor is applied to the impacting mass in order to ensure that the calculation results in no force being imparted to the specimen before impact. Freidenberg reports factors ranging from 1.0 to 1.4 [16]. The results of the peak pressures and impulses for each of the BGs is given in Table 1. The average peak impulse for the $17 \mathrm{~m} / \mathrm{s}$ test was calculated to be $4.4 \mathrm{MPa}-\mathrm{ms}$ (637 psi-ms) and the average peak impulse for the $22 \mathrm{mps}$ test was calculated to be $5.1 \mathrm{MPa}-\mathrm{ms}$ ( $733 \mathrm{psi}-\mathrm{ms}$ ).

The specimens for both the $17 \mathrm{~m} / \mathrm{s}$ and $22 \mathrm{~m} / \mathrm{s}$ test exhibited damage in the concrete and CFRP. For both tests cracks in the concrete wall, spall failure and failure of the composite were observed. Both tests exhibited the same failure modes:

- Spall failure of the concrete resulted in separation of the CFRP from the wall. This separation was not due to any bonding problem as a thin layer of concrete can be observed attached to the composite, but is a result of the low tensile strength of the concrete.

- Tearing of the CFRP was generally observed at locations of strain concentrations such as at the anchors.

- Certain tension failures were seen at the specimen boundaries, which may be an artifact of the test setup.

Table 1: Test matrix.

\begin{tabular}{llcc}
\hline Test & BG & Peak Pressure (MPa, psi) & Impulse (MPa-ms, psi-ms) \\
\hline 17 mps & BG 1 (bottom) & $3.96,574$ & $3.68,534$ \\
& BG 2 & $4.94,717$ & $4.34,630$ \\
& BG 3 & $6.21,900$ & $5.14,746$ \\
& BG 4 (top) & $3.78,548$ & $3.83,555$ \\
& Average & $4.72,685$ & $4.25,616$ \\
& BG 1 (bottom) & $8.28,1,201$ & $5.23,758$ \\
& BG 2 & $11.54,1,674$ & $5.05,732$ \\
& BG 3 & $7.12,1,033$ & $4.80,696$ \\
& BG 4 (top) & $2.76,401$ & $3.11,451$ \\
& Average & $7.43,1,078$ & $4.54,659$ \\
\hline
\end{tabular}




\section{SDOF ANALYSIS}

Single degree-of-freedom (SDOF) analyses have been used to predict the dynamic response of simple structural components subjected to blast loading [17, 18]. An SDOF analysis, assuming a hinge failure at the midpoint of the specimen, a uniformly-distributed load, and simply supported boundary conditions, was created for this test series. The average pressure and impulses from both the $17 \mathrm{~m} / \mathrm{s}$ and $22 \mathrm{~m} / \mathrm{s}$ test were used to approximate the idealized triangular blast loads as the blast load for the SDOF. For the $22 \mathrm{~m} / \mathrm{s}$ test, however, the fourth BG was not included in the average pressure and impulse calculation due to what is believed to be faulty measurements.

\subsection{Resistance function development \& results}

The resistance function for the test specimen was calculated as outlined in [19]. The resistance function was calculated following the assumption that the system was simply supported at the top and bottom boundary conditions (which were partially restrained in the experiments), resulting in the system forming a plastic hinge in the middle. The CFRP was included in the analysis by assuming that it behaves like the tensile reinforcement in the concrete, similar to the SDOF analysis performed by Myers et al. [20]. The contribution of the flexural strength due to the CFRP was calculated as outlined in the guidelines of ACI 440.2R-08 [21]. The average tensile strength obtained from the coupon tests was used as the yield strength of the CFRP, and the average rupture strain was used as the ultimate rupture strain of the CFRP for the flexural-strength calculation. It was ensured that strain compatibility and force equilibrium were met in this calculation. The overall cross-sectional area of the CFRP applied to the back face of the concrete wall (total CFRP thickness multiplied by the width of the wall) was used as the area of reinforcement. A reduction factor of 0.85 as recommended by ACI 440.2R-08 was applied to the CFRP flexural-strength contribution. This SDOF model allows for the calculated CFRP debonding strain to control the problem. The SDOF analysis indicated that the CFRP debonding strain did in fact control the flexural failure of the system, and that the system behaved in a brittle manner as the steel reinforcement did not yield. While the SDOF model was capable of accounting for the fact that the full tensile capacity of the CFRP was not reached, it was not capable of accounting for localized tearing that occurred in the CFRP or the partially restrained boundary conditions. The maximum displacement of the middle of the wall for the $17 \mathrm{~m} / \mathrm{s}$ test was overestimated in the SDOF analysis by $40.4 \%$ and the maximum displacement of the wall for the $22 \mathrm{~m} / \mathrm{s}$ test was underestimated in the SDOF analysis by $28.1 \%$. The displacement and resistance obtained from the SDOF analysis are shown in Fig. 3.

\section{FINITE ELEMENT MODEL}

The results of the SDOF models of the previous section overestimated the maximum displacement at the midpoint of the $17 \mathrm{~m} / \mathrm{s}$ test and underestimated the maximum displacement at the midpoint of the $22 \mathrm{~m} / \mathrm{s}$ test. It is suspected that these discrepancies are partially due to the nature of how the loads imparted to the specimen are calculated and partially because the wall systems exhibited failure modes such as CFRP tearing and CFRP separation from the wall due to spall failure which are not captured in the flexural response SDOF. Because of this, a higher fidelity finite element model was developed in order to better predict these modes. 

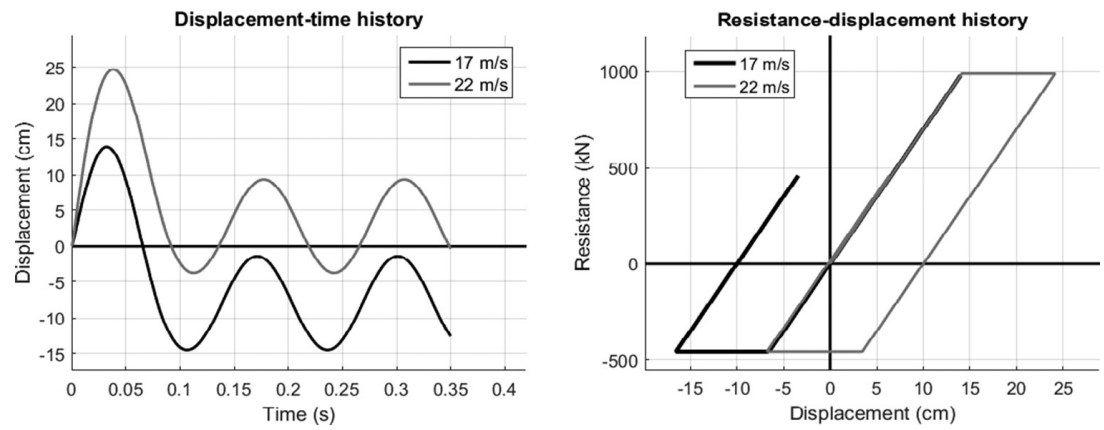

Figure 3: Displacements and resistance functions for SDOF model.

\subsection{LS-DYNA model}

A finite element model shown in Fig. 4 was created for use in LS-DYNA [22]. Half-symmetry was used in the numerical model with the appropriate symmetry boundary conditions. The reinforcement was explicitly modeled as beam elements and then merged into the concrete wall solid elements. Hughes-Liu beam element formulation with cross section integration was used to model the reinforcement. The concrete wall solid elements were modeled as eight-node brick elements with constant stress throughout the element. The CFRP was modeled with shell elements as a single homogeneous layer, with an appropriate total thickness of $0.5 \mathrm{~cm}(0.2 \mathrm{in})$, as the specimens were retrofitted with four layers of CFRP and manufacturer reported thicknesses of a single composite layer in resin around $0.1 \mathrm{~cm}(0.04 \mathrm{in})$. The CFRP shell elements were modeled using the Belytschko-Lin-Tsay element formulation. More information on the Belytschko-Lin-Tsay shell element formulation and the Hughes-Liu beam element formulation can be found in the LS-DYNA Theory Manual [23].

The top boundary was modeled on the back-face of the specimen as a concrete block. On the front face of the wall in one of the experiments, rubber inserts and steel angles were used to limit displacements at the top boundary. These were modeled explicitly for this test in the simulation, and were not included in the model for the other test. The bottom boundary was modeled on the back-face as a concrete block and on the front face the rubber insert and steel angle used in the experiments were included in the model. The rubber for both the top and bottom boundaries was modeled using the Blatz-Ko Foam model which was created for the use of rubber-like foams. The steel angles for both the top and bottom boundary conditions were modeled using the Piecewise Linear Plasticity model, where the defined stress-strain curve allowed for strain hardening. The modeled boundary conditions are shown in Fig. 4. Gravity was also modeled explicitly in pseudo-time (time before the actual loading of the test begins). Dynamic relaxation was implemented in the simulation so as to not have a noisy response due to the inclusion of gravity. The pseudo-time ends when the specified convergence tolerance $(0.174)$ for dynamic relaxation is met.

Contact surfaces were specified in the model between the different materials. The contact surfaces between the specimen and the explicitly modeled boundary conditions were defined using the Automatic Surface to Surface contact in LS-DYNA, which allows for penetration on either side of the surface's elements to be checked in each time-step. Additional contact surfaces were specified in order to capture localized effects from the anchorage system on the 


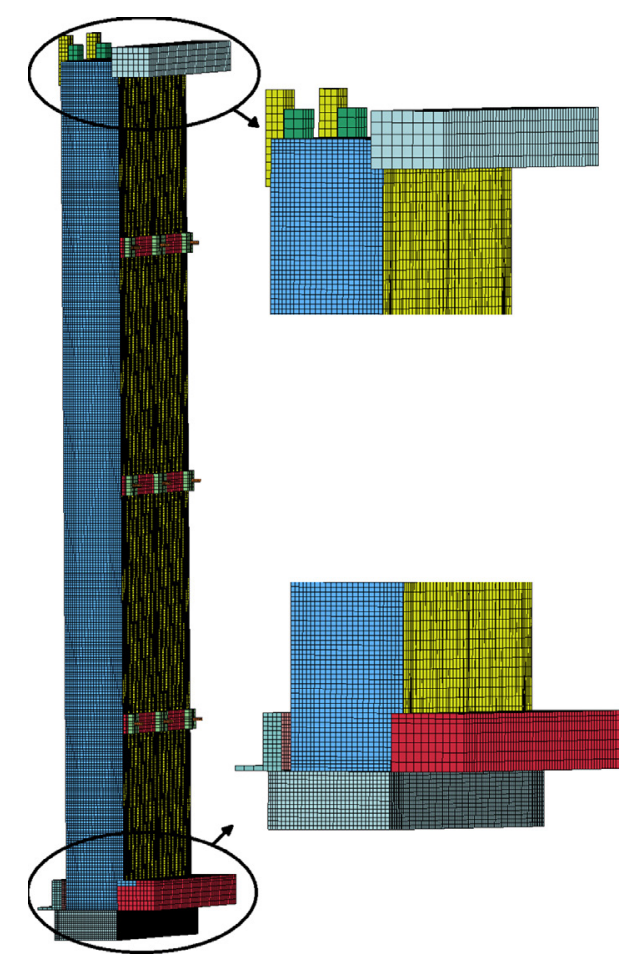

Figure 4: LS-DYNA finite element model (left) and explicitly modeled boundary conditions (right).

CFRP. A tiebreak criterion was specified between the CFRP layer of shell elements and the concrete wall which allowed nodes initially in contact to remain tied together until one or more of the failure criteria was met. Values for the contact frictional and tiebreak values were altered in order to find good agreement between the computational analysis and experimental results for the $17 \mathrm{~m} / \mathrm{s}$ test. This model formulation was then used, without variation, for the $22 \mathrm{~m} / \mathrm{s}$ test in order to validate the predictability of this computational analysis.

The loading in the computational model was derived directly from the experimental data as described previously. Segment sets on the front side of the specimen were defined to correspond to the area of impact for each BG. These segment sets were then loaded with the calculated pressure time histories for each corresponding BG.

\subsection{Material models}

Concrete cylinders from the concrete of the test specimen were tested and had a compressive strength of $38 \mathrm{MPa}(5,550 \mathrm{psi})$ at the day of testing for the first specimen. The concrete wall was modeled with $41 \mathrm{MPa}$ (6,000 psi) compressive strength, for simplicity. The Continuous Surface Cap material model (CSCM, or Material number 159 in LS-DYNA), was used to model all concrete materials in these test simulations. The use of CSCM has been evaluated to model concrete for various load types and strain rates [24]. This model was originally developed to simulate the concrete behavior in car crashes in order to improve the safety of 
Table 2: CFRP Properties.

\begin{tabular}{ll}
\hline Density $p, g * \mathrm{~cm}^{-3}$ & 1.20 \\
Tensile modulus, $E_{A}, E_{B}, E_{C}, \mathrm{MPa}$ & $2.86 \mathrm{e}+3,2.86 \mathrm{e}+3,7.22 \mathrm{e}+3$ \\
Poisson's ratio, ${ }^{v} B A,{ }^{v} C A,{ }^{v} C B$ & $0.0543,0.132,0.132$ \\
Shear modulus, ${ }^{G} A B,{ }^{G} B C,{ }^{G} C A, \mathrm{MPa}$ & $1.5 \mathrm{e}+3,1.54 \mathrm{e}+3,1.54 \mathrm{e}+3$ \\
Longitudinal tensile strength, $X_{T} \mathrm{MPa}$ & 503 \\
Transverse tensile strength, $Y_{T,} \mathrm{MPa}$ & 503 \\
Compressive strength, $X_{C}$ and $Y_{C}, \mathrm{MPa}$ & 290 \\
Shear strength, $S_{C}, \mathrm{MPa}$ & 48.3 \\
Effective failure strain, $E_{F S}$ & 0.017 \\
\hline
\end{tabular}

roadways, sponsored by the Federal Highway Administration. The yield surface of the model is a three stress invariant yield surface and exhibits a hardening cap that can expand and contract depending on user inputs. This model accounts for strain rate effects by increasing strength for high-strain rate loads. Erosion is allowed in this model based on damage and strain. Ductile damage and brittle damage are calculated separately to obtain the damage accumulation for each timestep. Concrete hardening due to pore compaction is also captured in this model. More details on the theory of this model can be found in Yvonne Murray's Users Manual [25]. All of the concrete components were modeled as 8-node solid brick elements. An erosion value of 1.15 was used in the simulations.

The material properties for the composite layers were given by the manufacturer. Using the theory provided by Jones [26], appropriate properties for the layup used in this test series were calculated. The CFRP properties can be seen in Table 2. The LS-DYNA enhanced composite damage material model was used to simulate the CFRP behavior. The Chang matrix failure criterion was used to indicate element failure, where tensile fiber, compressive fiber, tensile matrix, and compressive matrix failure criteria, are all separately specified by the user and each criterion is checked in each timestep. More information on this failure criteria can be observed in the LS-DYNA Theory manual [23]. The results comparing the coupon testing versus the model prediction are shown in Fig. 5.

\subsection{Results}

The displacement results of the $17 \mathrm{~m} / \mathrm{s}$ simulation compared to the experiment at the same load level can be seen in Fig. 6. This figure illustrates the maximum lateral displacements for specific heights of the wall. The maximum displacement of the wall from the finite element model was within $1.8 \%$ of the maximum displacement from the experimental results. It should be reminded that this was the test that was used to calibrate the finite element model. The displacement results of the $22 \mathrm{~m} / \mathrm{s}$ simulation compared to the experiment at the same load level can also be seen in Fig. 6. The maximum displacement of the wall from the finite element results only underestimated the displacement from the experimental measurements by $1.2 \%$, and the general shape of the displacement along the height matches the experimental displacement with little variation.

\section{CONCLUSIONS}

Large concrete wall specimen with an anchored CFRP retrofit were tested in the UCSD Blast Simulator. The experimental program provided information on modes of failure 


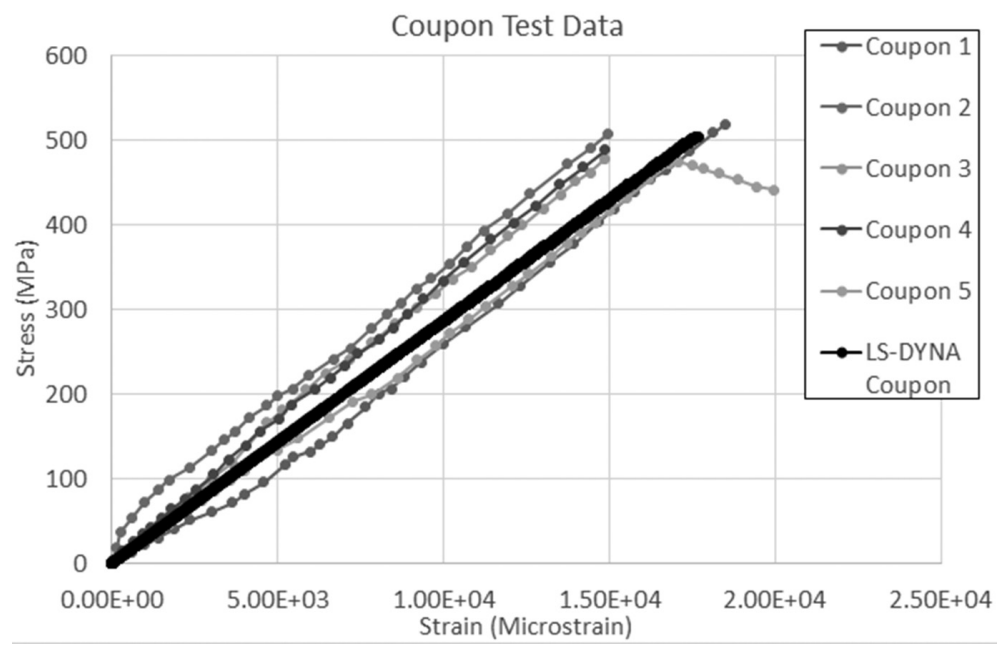

Figure 5: LS-DYNA comparison to CFRP coupon tests.
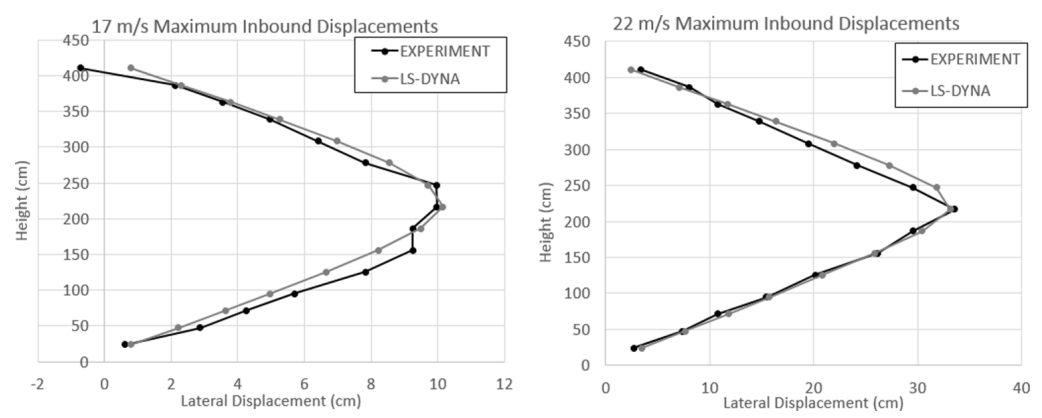

Figure 6: Maximum displacement comparisons.

(i.e. separation of CFRP from spall failure, CFRP tearing) as well as the maximum displacement of the wall system. Two analysis methods were considered: SDOF and LS-DYNA finite element analysis. The SDOF model, due to the partially restrained boundary conditions and non-flexural failure modes did not closely predict the maximum displacement at the midpoint of the wall. A high fidelity model was created in LS-DYNA to better model the experiments. This model utilized the continuous surface cap model and the enhanced composite damage material model with erosion. The concrete and composite interface was modeled with a contact tiebreak calibrated to one of the two experiments. The computational model, without variation, was able to predict the response of the second test with little variation.

\section{REFERENCES}

[1] Bonacci, J. \& Maalej, M., Behavioral trends of rc beams strengthened with externally bonded frp. Journal of Composites for Construction, 5(2), pp. 102-113, 2001.

http://dx.doi.org/10.1061/(ASCE)1090-0268(2001)5:2(102) 
[2] Hwang, S.J., Tu, Y.S., Yeh, Y.H. \& Chiou, T.C., Reinforced concrete partition walls retrofitted with carbon fiber reinforced polymer. ANCER Annual Meeting: Networking of Young Earthquake Engineering Researchers and Professionals, 2004.

[3] Buchan, P. \& Chen, J., Blast resistance of frp composites and polymer strengthened concrete and masonry structures-a state-of-the-art review. Composites Part B: Engineering, 38(5), pp. 509-522, 2007.

http://dx.doi.org/10.1016/j.compositesb.2006.07.009

[4] Wu, C., Oehlers, D., Rebentrost, M., Leach, J. \& Whittaker, A., Blast testing of ultra-high performance fibre and frp-retrofitted concrete slabs. Engineering Structures, 31(9), pp. 2060-2069, 2009.

http://dx.doi.org/10.1016/j.engstruct.2009.03.020

[5] Mosalam, K.M. \& Mosallam, A.S., Nonlinear transient analysis of reinforced concrete slabs subjected to blast loading and retrofitted with cfrp composites. Composites Pari B: Engineering, 32(8), pp. 623-636, 2001.

[6] Triantafillou, T., Strengthening of structures with advanced frps. Progress in Structural Engineering and Materials, 1(2), pp. 126-134, 1998.

http://dx.doi.org/10.1002/pse.2260010204

[7] Orton, S., Wheeler, M. \& Chiarito, V., Evaluation of mechanical anchoring system to improve performance of cfrp mitigated concrete slabs under close-in blasts. Structures Congress 2013@sBridging Your Passion with Your Profession, ASCE, pp. 239-249, 2013.

[8] Hamouda, A. \& Hashmi, M., Testing of composite materials at high rates of strain: advances and challenges. Journal of Materials Processing Technology, 77(1), pp. 327-336, 1998.

http://dx.doi.org/10.1016/S0924-0136(97)00436-6

[9] Orton, S.L., Chiarito, V.P., Rabalais, C., Wombacher, M. \& Rowell, S.P., Strain rate effects in cfrp used for blast mitigation. Polymers, 6(4), pp. 1026-1039, 2014. http://dx.doi.org/10.3390/polym6041026

[10] Chan, S., Fawaz, Z., Behdinan, K. \& Amid, R., Ballistic limit prediction using a numerical model with progressive damage capability. Composite Structures, 77(4), pp. 466-474, 2007. http://dx.doi.org/10.1016/j.compstruct.2005.08.022

[11] Mutalib, A.A. \& Hao, H., Numerical analysis of frp-composite-strengthened rc panels with anchorages against blast loads. Journal of Performance of Constructed Facilities, 25(5), pp. 360-372, 2010.

http://dx.doi.org/10.1061/(ASCE)CF.1943-5509.0000199

[12] Eshwar, N., Nanni, A. \& Ibell, T.J., Performance of two anchor systems of externally bonded fiber-reinforced polymer laminates. Materials Journal, 105(1), pp. 72-80, 2008.

[13] Kalfat, R., Al-Mahaidi, R. \& Smith, S.T., Anchorage devices used to improve the performance of reinforced concrete beams retrofitted with frp composites: State-of-the-art review. Journal of Composites for Construction, 17(1), 2011.

[14] Muszynski, L.C. \& Purcell, M.R., Use of composite reinforcement to strengthen concrete and air-entrained concrete masonry walls against air blast. Journal of Composites for Construction, 7(2), pp. 98-108, 2003. http://dx.doi.org/10.1061/(ASCE)1090-0268(2003)7:2(98) 
[15] Stewart, L., Freidenberg, A., Rodriguez-Nikl, T., Oesterle, M., Wolfson, J., Durant, B., Arnett, K., Asaro, R. \& Hegemier, G., Methodology and validation for blast and shock testing of structures using high-speed hydraulic actuators. Engineering Structures, 70, pp. 168-180, 2014.

http://dx.doi.org/10.1016/j.engstruct.2014.03.027

[16] Freidenberg, A., Advancements in blast simulator analysis demonstrated on a prototype wall structure. University of California San Diego, Dissertation Thesis, 2013.

[17] Fischer, K. \& Häring, I., Sdof response model parameters from dynamic blast loading experiments. Engineering Structures, 31(8), pp. 1677-1686, 2009. http://dx.doi.org/10.1016/j.engstruct.2009.02.040

[18] Krauthammer, T., Shahriar, S. \& Shanaa, H., Response of reinforced concrete elements to severe impulsive loads. Journal ofStructural Engineering, 116(4), pp. 1061-1079, 1990.

[19] Biggs, J.M. \& Testa, B., Introduction to Structural Dynamics, volume 3. McGraw-Hill: New York, 1964.

[20] Myers, J.J., Belarbi, A. \& El-Domiaty, K.A., Blast resistance of frp retrofitted un-reinforced masonry (urm) walls with and without arching action. The Masonry Society Journal, 22(1), pp. 9-26, 2004.

[21] 440, A.C., ACI 440.2R-08 - Guide for the Design and Construction of Externally Bonded FRP Systems for Strengthening Concrete Structures. American Concrete Institute, Farmington Hills, MI, 2008.

[22] Coporation, L.S.T., LS-DYNA(R) Keyword User's Manual Volume I. Livermore Software Technology Coporation, Stanford, California, 2007.

[23] Coporation, L.S.T., LS-DYNA(R) Theory Manual. Livermore Software Technology Coporation, Stanford, California, 2006.

[24] Murray, Y.D., Abu-Odeh, A. \& Bligh, R., Evaluation of LS-DYNA Concrete Material Model 159. U.S. Department of Transportation, Mclean, VA, 2007.

[25] Murray, Y.D., Users Manual LS-DYNA Concrete Material Model 159. U.S. Department of Transportation, Mclean, VA, 2007.

[26] Jones, R.M., Mechanics of Composite Materials, volume 193. Scripta Book Company: Washington, DC, 1975. 